\title{
Developing an affirmative position statement on sexual and gender diversity for psychology professionals in South Africa
}

\author{
Cornelius J. Victor, Juan A. Nel${ }^{\star}$ \\ Department of Psychology, University of South Africa, Pretoria, Republic of South Africa
}

*Corresponding author. E-mail: nelja@unisa.ac.za

Background. Against the background of the dominance of patriarchy and heteronormativity in Africa and the resultant stigma, discrimination and victimisation of sexually and gender-diverse people, this article reports on the development of an affirmative position statement by the Psychological Society of South Africa (PsySSA) for psychology professionals working with sexually and gender-diverse people. The position statement is an attempt to contribute positively to the de-stigmatisation, amongst psychology professionals, of all people with diverse sexual and gender identities.

Objective. In documenting and reflecting on the process of developing the statement - a first on the African continent - the article aims to contribute to the potential resources available to others in their work on similar projects around the world.

Design. Although initially intended to be relevant to the African continent, the position statement is appropriate to the South African context specifically, but developed in consultation with a range of stakeholders, also from other African countries.

Results. Concerns expressed during stakeholder consultations, and thus taken into account in the development of the statement, include relevance to other African countries, negotiating the politics of representation and language, the importance of including gender and biological variance in addition to sexuality, and the need to be sensitive to how Western influence is constructed in some African contexts.

Conclusion. Other national psychology organisations stand to benefit by 'lessons learned' during this country-specific process with global implications, especially with respect to broadening the lens from lesbian, gay, bisexual, transgender and intersex (LGBTI) to sexual and gender diversity, as well as an acknowledgement of the multiple and fluid developmental pathways around sexuality and gender, in general.

Keywords: affirmative stance, LGBTI psychology, position statement, PsySSA, sexual and gender diversity 


\section{Introduction}

Over the past few years, dramatic advancements in lesbian, gay, bisexual, transgender and intersex (LGBTI) rights have been visible across much of the globe. In many African countries, though, discrimination, persecution and in some cases criminal prosecution have continued. In comparison to elsewhere on the continent, the situation in South Africa differs significantly, given this country's progressive constitutional and legal framework protecting the rights of all, and driving reform aimed at preventing discrimination and promoting equality, amongst others, based on gender, biological sex and sexual orientation ${ }^{1}(\mathrm{Nel}, 2014)$.

Nevertheless, there are stark discrepancies between constitutional and legal equality based on gender and sexual orientation, and the continued stigma, discrimination and violence still faced by many South Africans. Similarly, practices in mainstream mental healthcare often reflect a lack of an affirmative approach and instances of secondary victimisation of LGBTI persons. Against this background, the Psychological Society of South Africa (PsySSA) African LGBTI Human Rights Project was launched in 2011. One overall aim of this project was the development of affirmative psychological practice guidelines that can be applied or adapted throughout Africa. A first step in this journey was the development of a position statement regarding sexual and gender diversity, including LGBTI concerns (Victor, Nel, Lynch, \& Mbatha, 2014).

1 A comprehensive glossary of terms can be found in Victor et al. (2014), including the following:

Biological sex. The biological and physiological characteristics that are socially agreed upon as informing the classification of a person as male or female.

Cisgender. A term describing a person whose perception and expression of her or his own gender identity matches the biological sex she or he was assigned at birth.

Gender. The socially constructed roles, behaviour, activities and attributes that a society considers appropriate for either men or women.

Gender diversity. The range of different gender expressions that spans across the historically imposed male-female binary. Referring to 'gender diversity' is generally preferred to 'gender variance' as 'variance' implies an investment in a norm from which some individuals deviate, thereby reinforcing a pathologising treatment of differences among individuals.

Intersex. A term referring to a variety of conditions (genetic, physiological or anatomical) in which a person's sexual and/or reproductive features and organs do not conform to dominant and typical definitions of 'female' or 'male'. Such diversity in sex characteristics is also referred to as 'biological variance', a term which risks reinforcing pathologising treatment of differences among individuals, but which is used with caution in this document to indicate an inclusive grouping of diversity in sexual characteristics, including, but not limited to, intersex individuals.

Sexual diversity. The range of different expressions of sexual orientation and sexual behaviour that spans across the historically imposed heterosexual-homosexual binary.

Sexual orientation. A person's lasting emotional, romantic, sexual or affectional attraction to others (heterosexual, homosexual/same-sex sexual orientation, bisexual or asexual).

Transgender. A term for people who have a gender identity and often a gender expression that is different to the sex they were assigned at birth by default of their primary sexual characteristics. The term is also used to refer to people who challenge society's view of gender as fixed, unmoving, dichotomous, and inextricably linked to one's biological sex. Gender is viewed more accurately as a spectrum, rather than a polarised, dichotomous construct. This broad term encompasses transsexuals, gender queers, people who are androgynous, and those who defy what society tells them is appropriate for their gender. Transgender people can be heterosexual, bisexual, homosexual or asexual. 
In this article, an initial focus is placed on the process of developing the position statement and the institutional and social background against which the statement was conceived of, before providing a brief introduction to the affirmative stance informing the statement. Specific attention is given to concerns raised during the consultation process by stakeholders, also from other African countries. These concerns, among others, relate to -

- relevance to other African countries;

- negotiating the politics of representation and language;

- the inclusion of gender diversity in addition to sexuality;

- sensitivity to multiple and fluid sexual and gender identities; and

- the need to be sensitive to how Western influence is constructed in some African contexts.

The discussion is rounded off by highlighting the ways in which the position statement has been disseminated and some reactions from practitioners and others in the broader healthcare environment in South Africa, and elsewhere. By reflecting on the process of developing and disseminating the statement the hope is also to contribute to the potential resources available to others globally in their work on similar projects.

\section{The PsySSA African LGBTI Human Rights Project}

PsySSA is a non-profit, professional association of persons involved in the academic, research and practical application of the discipline of psychology. PsySSA, established in 1994, is the nationally representative learned society for psychology in South Africa, and is recognised as such by the International Union of Psychological Science (IUPsyS). As per its constitution, PsySSA is committed to the transformation and development of South African psychology to serve the needs and interests of all the people of South Africa, and it aims to advance psychology as a science, a profession and as a means of promoting human wellbeing (PsySSA, 2011).

As part of its efforts to achieve these aims, PsySSA is a member of the International Psychology Network for Lesbian, Gay, Bisexual, Transgender and Intersex Issues (IPsyNET). ${ }^{1}$ IPsyNET is comprised of national, multinational and international psychological associations. These associations are cooperating to increase international collaboration and knowledge amongst practitioners concerned with LGBTI issues, stimulate and apply psychological research and guidelines that address the needs and concerns of LGBTI populations, and increase the number of psychological associations that reject the notion of same-sex sexuality as a mental disorder and promote affirmative mental health practice for LGBTI people (IPsyNET, 2013).

The American Psychological Association's (APA) Lesbian, Gay, Bisexual, and Transgender Concerns Office (LGBTCO) has served as the secretariat of IPsyNET since its inception in 2001, then known as the International Network for Lesbian, Gay, and Bisexual Concerns and Transgender Issues in Psychology (INET). Through funding provided by the Arcus Foundation, the LGBTCO has been able to provide financing and technical expertise to PsySSA. Limited additional funding support by HIVOS MAGI (Multi-agency Grants Initiative) and the University of South Africa enabled the launch of the PsySSA African LGBTI Human Rights Project in 2011. 
The objective of the PsySSA African LGBTI Human Rights Project is to assist PsySSA in becoming a regional hub to promote capacity and membership of other psychological associations throughout Africa in the work of IPsyNET and to foster active and vocal regional participation in debates around LGBTI issues and concerns (Victor et al., 2014).

\section{Context and aim of the position statement}

South Africa has seen significant socio-legal and policy developments in the protection of the human rights of all people in the country, and respect for diversity and concomitant non-discrimination based on, amongst others, gender and sexual orientation (Republic of South Africa, 1996). These developments have brought about changes at an institutional and disciplinary level with, for instance, the ethical code for health professionals, including a focus on human rights, diversity and non-discrimination within a general do-no-harm framework (Department of Health, 2006).

However, the aforementioned developments have not necessarily effected changes at a broader societal level. Sexualities remain heavily influenced by patriarchal systems that privilege heterosexuality (Jackson, 2006). A patriarchal and heteronormative model of gender and sexuality perpetuates unequal power relations between men and women, and entrenches male privilege, contributing to high levels of sexual- and gender-based violence against women in South Africa (Dartnall \& Jewkes, 2013). Further to this, such a rigid and oppressive model of gender and sexuality limits the courses of action available to men, in that a normative male identity is associated with expectations of invulnerability and self-reliance, contributing to risky sexual behaviour and low rates of health-seeking behaviour among many South African men (Lynch, Brouard, \& Visser, 2010). Public attitudes in South Africa to same-sex sexuality remain overwhelmingly negative, with a nationally representative survey indicating that $84 \%$ of the population say that it is always wrong for two adults of the same sex to have sexual relations (Smith, 2011). Human rights violations and hate crimes against sexual and gender non-conforming minorities are also increasingly being reported (Human Rights Watch, 2011).

Current healthcare provision in South Africa is generally based on the assumption of similarity rather than acceptance of diversity (Rispel \& Metcalf, 2009). Given the prevalence of discrimination at public health facilities, LGBTI people are less likely to access healthcare in the public sector (Stevens, 2012; Wells \& Polders, 2003). In recognition of this, and to assist psychology professionals in South Africa in their related endeavours, an affirmative position statement on sexual and gender diversity, including LGBTI concerns, was developed. This position statement supplements the harm-avoidance approach present in the South African Health Professions Act (Department of Health, 2006) by outlining specific themes for psychology professionals to consider in assuming an affirmative stance.

\section{Exploring an affirmative stance}

The development of a South African position statement that is affirmative of sexual and gender diversity follows similar initiatives by other professional associations. These include: 
- the American Psychological Association Practice guidelines for lesbian, gay and bisexual clients adopted in 2000 and updated in 2011 (American Psychological Association [APA], 2011);

- the British Psychological Society Guidelines and literature review for psychologists working therapeutically with sexual and gender minority clients (British Psychological Society [BPS], 2012);

- the World Professional Association for Transgender Health (WPATH) Standards of care for the health of transsexual, transgender, and gender nonconforming people (WPATH, 2011);

- the Statement of the Psychological Association of the Philippines on nondiscrimination based on sexual orientation, gender identity and expression (Psychological Association of the Philippines, 2011); and

- the Hong Kong Position paper for psychologists working with lesbians, gays, and bisexual individuals (Hong Kong Psychological Society: Division of Clinical Psychology, 2012).

The term 'affirmative psychotherapy' was initially developed in relation to sexual orientation (thus lesbian, gay and bisexual [LGB]), only), and it is therefore firstly discussed in this article from such a position only. Although with different emphases, some common elements in affirmative approaches to LGB sexualities are apparent in the work of a variety of authors, such as Davies (1996), Milton, Coyle, and Legg (2002), and Ritter and Terndrup (2002). These authors concur that an affirmative approach includes that sexual diversity, per se, should not be seen as the cause of psychological difficulties or pathology; the perspective is rather one of recognition of LGB sexualities as normal and natural variances on human sexuality. It is important that the practitioner takes contextual factors into account, in particular how homophobia, heteronormativity, prejudice and stigma influence mental health and wellbeing, and acknowledges the influence of society and significant others on the LGB client. Practitioners also need to be able to empathise with the experiences of LGB clients, including being knowledgeable about LGB sexualities, diversity of identities and experiences within LGB communities, and lifestyles. An affirmative approach implies that practitioners ought to be comfortable in exploring their own sexualities to avoid their potential personal biases affecting their practice. Taking an actively positive view of LGB lives includes assuming that LGB clients have the potential creativity and internal resources to deal with their difficulties and problems (Davies, 1996; Milton et al., 2002; Ritter \& Terndrup, 2002).

Practitioners need to focus on the way their clients describe themselves, rather than imposing technical language. Practitioners furthermore need to provide a space for clients to explore their possible identities, instead of assuming a particular endpoint. In addition, therapeutic efforts aimed at such a specific endpoint, for instance gender conformity or a heterosexual orientation, are potentially harmful, dangerous and in conflict with medical ethics and should be avoided (Academy of Science of South Africa, 2015). As is later indicated, such an affirmative lens could be applied to all people who walk through a professional's door, and implies a cultivated and ongoing sensitivity to and acceptance of sexual and gender diversity. 


\section{Establishing the working group}

The development of the South African position statement serves as a first step in achieving the longer-term goal of the PsySSA African LGBTI Human Rights Project to establish affirmative psychological practice guidelines that may or may not also be relevant elsewhere in Africa. Towards this objective, representatives from across Africa were identified and recruited to attend a pre-congress workshop at the International Congress of Psychology held in Cape Town South Africa in July 2012. The pre-congress workshop, attended by 38 people, provided an ideal platform to bring together experts and interested parties to discuss the possibility of developing affirmative practice guidelines in relation to sexual and gender diversity in Africa (Victor, 2012).

The workshop culminated in the establishment of a working group of 24 members, constituted of stakeholders and mental health professionals spanning South Africa, Nigeria, Cameroon, Uganda and Tanzania, tasked with the development of the guidelines. The workshop highlighted several issues that would be important to consider in developing practice guidelines for Africa and prompted discussions regarding the advantages and disadvantages associated with first developing a position statement for South Africa before proceeding to practice guidelines with relevance for the continent (Victor, 2012). The main debates emerging from the workshop are discussed below.

\section{The challenges and debates in developing African guidelines}

Debating the guidelines development process commenced with agreeing that psychology as a discipline is significantly underdeveloped in Africa. On the African continent, psychological wellbeing is often achieved through avenues other than professional services, including traditional healers and clergy (Campbell-Hall et al., 2010). A first challenge thus presented itself: in this context, focusing only on guidelines for the discipline of psychology can be exclusionary as there is a need to consider other healthcare and mental health workers, such as volunteers, traditional healers and related healing systems. Accordingly, it was agreed during the workshop that, whilst this was an initiative from the discipline of psychology, an opportunity presented itself to develop guidelines for professionals within a broader mental health arena. In developing the guidelines, the suggestion was thus that care be taken to ensure that the document reflected this wider target set, both in theory and application.

An important conceptual concern raised during the workshop was that the privileging of individual human rights is not universally accepted in all parts of Africa (Academy of Science of South Africa, 2015). In developing the guidelines, inclusive of LGBTI concerns, different regions and countries in Africa would need to be sensitive to whether a human rights perspective would necessarily provide the most acceptable entry point. An alternative stance is that of positioning LGBTI concerns within a mental health and wellbeing framework. It was agreed that such a framework, which emphasises competent healthcare service provision, could be particularly valuable in contexts where same-sex practices remain subject to constitutional and legal discrimination. 
A further conceptual theme centred on the utility of framing affirmative practice guidelines for the African context in relation to identity politics. Identity politics often rely on self-identified categories of sexual orientation and gender identity to raise consciousness around experiences of oppression related to particular identities (Mertus, 2007). In the United States, identity politics has provided a valuable frame for the development of affirmative practice guidelines in that LGB rights advocates within the APA had to assume an activist role to motivate why, despite homosexuality being declassified as a disorder in 1973, there remained a need for the discipline to formulate an affirmative stance on LGB concerns. The relevance of dominant Western analytical categories when researching African sexualities has however been questioned, and in the African context, the argument has been raised for the fluidity of sexuality and gender, instead of focusing on fixed notions of identity (Epprecht, 2006). Following from this, it was important to broaden the LGB focus when developing guidelines for African contexts to attend to sexual and gender diversity in general.

Accordingly, in developing the PsySSA position statement, the aim was to extend such an affirmative stance regarding sexual orientation to represent a wider inclusiveness of sexual and gender diversity with specific reference to LGBTI concerns, i.e. sexual orientation, gender identity and biological variance. This expanded lens also reflects similar global developments such as that of the $5^{\text {th }}$ edition of the Diagnostic and Statistical Manual of Mental Disorders (DSM) (American Psychiatric Association, 2013) moving away from pathologising positions around transgender concerns to a more affirmative approach, as well as the APA's Guidelines for psychological practice with transgender and gender nonconforming people (APA, 2015).

Related to the above, participants at the workshop suggested that expanding the view from single-identity politics to multiple dimensions of identities would also bring to the fore the interaction of various forms of oppression, such as those based on race and socio-economic status, which result in different forms of oppression affecting a person in interrelated ways. A lens that is sensitive to intersectionality (see APA, 2015) could not only potentially highlight the way heteronormative and patriarchal contexts have harmful consequences for LGBTI persons but also constrain the courses of action available to all people. Such contexts contribute to stigma, discrimination and victimisation, based on power differentials along varied lines of oppression. Acknowledgement of relevant intersectionalities could potentially avoid the pitfalls of taking an 'othering' stance and, instead, allow for reflection on how psychology professionals could challenge stigma and discrimination informed by unequal systems of sexuality and gender broadly.

Another concern raised during the workshop was that South Africa's leading role in the development of the sexual and gender diversity-related affirmative guidelines might be perceived as neo-colonialist and as furthering the aims of an imperialist agenda in other African countries. This concern was predominantly based on the way political leaders in several African countries have at times drawn on a discourse of same-sex sexuality being a 'Western import' and consequently regarded it as 'un-African', to substantiate a construction of an African identity separate from Western influence (Hoad, 2007). Following from this, guidelines that are 
affirming same-sex sexuality could potentially be resisted based on being regarded as un-African if their development is perceived as predominantly serving a South African agenda, a country at times associated with Western influence.

Sexuality and gender remain under-researched in Africa and there is a dearth of scientific evidence that could be drawn on to support the development of affirmative guidelines relevant to Africa (PsySSA, 2013). Discussions during the workshop reflected the view that, following the developmental path of more than twenty years, which culminated in establishing affirmative guidelines in the United States, was not tenable in the face of urgent concerns in the African context: the window of opportunity to develop guidelines presented itself at the time. This window was evidenced by the International Congress of Psychology held on African soil for the first time in 2012, as well as by the launch of the Pan-African Psychology Union (PAPU) in 2014 (Nel, 2014). PAPU is a professional body that could provide an opportunity for the development of a mutual Africa agenda around gender and sexuality, which is not driven by one country. In addition, establishing an African evidence base had to take into account different perspectives, particularly within indigenous contexts, of what constitutes knowledge and evidence. The group concurred that international research should be used as relevant and that gaps for further research in African contexts had to be identified and appropriate funding mechanisms developed to address such gaps.

In summary, reflections from the workshop shaped the focus of the PsySSA African LGBTI Human Rights Project to be cognisant of the broader healing systems drawn on in African contexts. The workshop sensitised the group to the following:

- the need for contextual sensitivity to the strategic benefit of a human rights position or a mental health and wellbeing position in advancing the interests of LGBTI persons;

- the relevance of framing this work in relation to fluidity in sexual and gender diversity;

- the importance of recognising the intersectionality of identities and experiences of discrimination and victimisation;

- the need to be sensitive to how Western influence is constructed in some African contexts; and

- the need to advance an affirmative view of sexual and gender diversity, while at the same time expanding the African body of knowledge available to inform such work.

\section{A position statement for South Africa}

Following the workshop, it became clear that creating practice guidelines for Africa, as a first step in this process, was neither realistic nor desirable. Different countries within Africa have vastly different understandings of human rights and the acceptance of sexual and gender diversity. Ideally, different African regions or countries would therefore need to develop their own guidelines to suit their local contexts. The involvement of a broader range of constituents at the development stage of the guidelines was however deemed critical, as this would ensure increased agreement with and acceptance of the process. In the face of these challenges, lim- 
ited financial and time resources and recognising the development and support in the discipline already available in South Africa, it was decided to redefine the aim of the project as constructing an affirmative position statement on sexual and gender diversity aimed at psychology professionals in South Africa and developed by PsySSA. The working group elected a core team to prepare this statement (see Acknowledgements for names). A period of intense activity followed between October 2012 and August 2013 with the team developing draft statements, presenting it to the working group and inviting further commentary and feedback from a wider group of stakeholders, mainly through e-mail communication with personal lists and known individuals in sexual and gender diversity work in South Africa. These efforts culminated in the draft statement being presented to the PsySSA Executive Committee and PsySSA Council for ratification - in effect, the highest decisionmaking body of the learned society for psychology in South Africa, thus serving as ethical clearance - and finally launched at the PsySSA Congress in September 2013 (PsySSA, 2013; Victor et al., 2014). In the following, sections of the position statement (PsySSA, 2013, pp. 8-10) are quoted verbatim.

"Recognising the harm that has been done in the past to individuals and groups by the prejudice against sexual and gender diversity in South African society as well as in the profession of psychology, PsySSA hereby affirms the following. Psychology professionals -

1. Respect the human rights of sexually and gender diverse people, and are committed to non-discrimination on the basis of sexuality and gender, including, but not limited to, sexual orientation, gender identity, and biological variance;

2. Subscribe to the notion of individual self-determination, including having the choice of self-disclosure (also known as 'coming out') of sexual orientation, gender diversity, or biological variance;

3. Acknowledge and understand sexual and gender diversity and fluidity, including biological variance;

4. Are aware of the challenges faced by sexually and gender diverse people in negotiating heteronormative, homonormative, cisgendered (see section 'Glossary'), and other potentially harmful contexts;

5. Are sensitised to the effects of multiple and intersecting forms of discrimination against sexually and gender diverse people, which could include discrimination on the basis of gender; sexual orientation; biological variance; socio-economic status, poverty, and unemployment; race, culture, and language; age and life stage; physical, sensory, and cognitive-emotional disabilities; HIV and AIDS; internally and externally displaced people and asylum seekers; geographical differences such as urban/rural dynamics; and religion and spirituality;

6. Have an understanding of stigma, prejudice, discrimination and violence, and the potential detrimental effect of these factors on the mental health and well-being of sexually and gender diverse individuals;

7. Recognise the multiple and fluid sexual and gender developmental pathways of all people from infancy, childhood, and adolescence into adulthood and advanced age; 
8. Understand the diversity and complexities of relationships that sexually and gender diverse people have, which include the potential challenges:
(a) of sexually and gender diverse parents and their children, including adoption and eligibility assessment;
(b) within families of origin and families of choice, such as those faced by parental figures, caregivers, friends, and other people in their support networks, for example, in coming to terms with the diversity, non- conformity, and/or minority status of their sexually and gender diverse significant other; and
(c) for people in different relationship configurations, including polyam- orous relationships.

9. Adhere to an affirmative stance towards sexual and gender diversity in policy development and planning, research and publication, training and education (including curriculum development, assessment, and evaluation of assessment tools), and intervention design and implementation (including psychotherapeutic interventions);

10. Support best practice care in relation to sexually and gender diverse clients by:

(a) using relevant international practice guidelines in the absence of South African-specific guidelines;

(b) cautioning against interventions aimed at changing a person's sexual orientation or gender expression, such as 'reparative' or conversion therapy;

(c) opposing the withholding of best practice gender-affirming surgery and treatment and best practice transgender healthcare as outlined by the WPATH; and

(d) encouraging parents to look for alternatives to surgical intervention in the case of intersex infants, unless for pertinent physical health reasons.

11. Are, if it be the case, aware of their own cultural, moral, or religious difficulties with a client's sexuality and/or gender identity, in which case they should disclose this to the client and assist her or him in finding an alternative psychology professional should the client so wish; and

12. Are committed to continued professional development regarding sexual and gender diversity, as well as to promoting social awareness of the needs and concerns of sexually and gender diverse individuals, which includes promoting the use of affirmative community and professional resources to facilitate optimal referrals."

\section{Issues considered in developing the position statement}

The process of developing the position statement brought with it renewed consideration of emphasis, contextual sensitivity and the anticipated utility of the document in the South African context. The statement itself outlines various positions in relation to sexual and gender diversity and moves from the general to the specific. It firstly addresses issues of human rights and self-determination, which is followed by - 
- introducing the idea of diversity and fluidity in sexuality and gender identity;

- challenges faced by sexually and gender-diverse people in negotiating heteronormative contexts;

- the influence of multiple and intersecting forms of discrimination on sexually and gender-diverse people;

- the influence of stigma, prejudice and discrimination on mental health;

- the recognition of multiple and fluid sexual and gender developmental pathways of all persons; and

- the complexities of relationships within a sexually and gender-diverse context.

The final components of the statement deal with assuming an affirmative stance, following best practice care, continued professional development, and the promotion of social awareness around sexual and gender diversity (PsySSA, 2013; Victor et al., 2014).

The decision to adopt an affirmative stance in the position statement was made early in the process and it remained a foundation against which the document was checked. As the draft position statement progressed, it was found that the understanding of an affirmative stance developed to include a broader area of sexual and gender diversity. This manifested in the statement by expanding references to 'LGBTI concerns' to refer to 'sexual and gender diversity' instead, in line with the views advanced during the workshop discussion. The decision to adopt this terminology was, firstly, based on an understanding that a broader set of people are facing the potentially negative effect of a heteronormative and homonormative, patriarchal society, which implies a shared struggle. Secondly, the affirmative statement could potentially hold increased utility and relevance for colleagues wanting to develop similar position statements in their respective African countries.

Some previous efforts in psychology, internationally, to develop position statements or guidelines on sexuality and gender have at times excluded transgender persons, and intersex concerns have seldom, if ever, featured (see for instance APA, 2011 and the Hong Kong Psychological Society: Division of Clinical Psychology, 2012). Following from this, where the position statement does make mention of LGBTI concerns specifically, it was ensured that gender identity and biological variance were attended to in addition to sexuality.

An implication of expanding the focus of the statement beyond LGBTI concerns to attend to sexuality and gender more broadly was the aim to avoid various forms of othering or exclusion. In doing so, it was not assumed that the practitioner is from a non-sexed/non-gender/non-raced/non-classed position, such as is often the case in existing ethical codes. Questions had to be asked around the difficulties faced by practitioners in working in predominantly heteronormative contexts and how the statement could assist them in dealing with societal prejudice related to sexuality and gender. In addition, the focus moved from the individual user only to the individual and his/her significant others and how stigma and discrimination affect them as well. 
The affirmative stance also had implications for the way language was treated in the document. The group felt it was important to use non-essentialist language as this provided a more open framework that recognises diversity. Essentialist language such as 'normal people' and 'normal preferences' were rephrased, and this also meant that the focus was placed more on affirmation of diversity and fluidity of gender and sexuality and less on specific minority groups. It was however felt that in some instances, it was still needed to include what might be thought of as essentialist terms, such as references to 'lesbian', 'gay', 'bisexual', 'transgender' and 'intersex' as categories of sexuality or gender identity. The reason for inclusion was that these terms would possibly be familiar to many and would also ensure that the positions of minorities and the specific stigma, discrimination and trauma they experience were not erased.

Considering the emphasis of an affirmative stance on contextual awareness, a key challenge in developing the position statement was to ensure that it was grounded in a South African body of knowledge. To this end, the small but growing body of work that constitutes South African LGBTI psychology was consulted during this process. Research on LGBTI people's experience with health providers in South Africa that was drawn on included -

- $\quad$ studies on gay men's experiences in psychotherapy groups (Nel, Rich, \& Joubert, 2007);

- the experience of LGB people with psychological therapy and counselling (Victor, 2013; Victor \& Nel, 2016);

- transgender people's experience with sexual health services (Stevens, 2012); and

- perceptions of healthcare providers around sexual orientation and treatment refusal due to sexual orientation (Rich, 2006; Wells, 2005; Wells \& Polders, 2003).

Local policy and practice guidelines that were consulted included -

- healthcare provision for victims of hate crime (Nel, 2007);

- guidelines for service providers working with lesbians and gay people (OUT LGBT Well-being, 2007);

- guidelines when working with men who have sex with men (MSM) in an HIV/AIDS health service context (Anova Health Institute, 2010); and

- indigenous comments on the WPATH's Standards of Care (Gender Dyna$\operatorname{miX}, 2011)$.

The structure and format of the position statement were driven by the practical utility of the document for psychology professionals in South Africa. While this may be different in other contexts, it was felt that information needs to be provided around the topic under discussion in the form of, for example, a comprehensive glossary that accompanies the statement. Knowing that the position statement would be followed by a more comprehensive guidelines document also provided the opportunity to ensure that the initial document outlined the position or view of PsySSA on the topic of sexual and gender diversity in the form of clear, succinct statements, rather than providing detailed practice guidelines. 


\section{Dissemination of, and reaction to, the position statement}

After the official launch of the position statement at the PsySSA Congress in September 2013, several other dissemination-related activities followed, including:

- publication in an academic journal (Victor et al., 2014);

- electronic distribution to all members of the PsySSA Sexuality and Gender Division;

- publication on the PsySSA website at www.psyssa.com;

- several related presentations at both local and international conferences and other forums, as well as handing out a printed version at these meetings; and

- training postgraduate master's students at several local universities.

The reaction to the statement has been exceptionally positive, both within the discipline of psychology, as well as in healthcare more generally. The statement is being used, amongst others -

- as a base to design training curricula for health professionals, ranging from nursing to psychiatry;

- as key input into the policy recommendations for African leaders regarding diversity in human sexuality (Academy of Science of South Africa, 2015);

- in the design of global core competencies for psychiatrists working with sexually and gender-diverse people under the auspices of the World Psychiatry Association in 2016; and

- to inform several related opinion pieces by the PsySSA Sexuality and Gender Division.

PsySSA itself considers this document a significant contribution to the discipline's efforts in ensuring the mental wellbeing of all South Africans, as well as a good benchmark for the development of position statements on other topics by the Society.

\section{Conclusion and the way forward}

The sexual and gender diversity position statement is the first to be developed by PsySSA on any issue in psychology and is also the first statement on sexual and gender diversity developed by a psychological association on the African continent. The statement is a much needed and important point of engagement for psychology professionals with the intricacies and complexities of human lived experience understood from an affirmative stance that is consciously inclusive of sexual and gender diversity. This is a stance of openness, acceptance and affirmation of diversity, and a respect for the unique and fluid lived experience of the client, service user or participant, which is open to adaptation and change, rather than an effort to force or coerce change according to preconceived notions and categories. The PsySSA African LGBTI Human Rights Project is currently in the process of developing South African practice guidelines for psychology professionals working with sexually and gender-diverse people. This will potentially be followed by collaboration with colleagues from the rest of Africa in developing statements and practice 
guidelines suited to their unique contexts. It is furthermore trusted that this article will contribute positively to the de-stigmatisation, amongst psychology professionals, of all people with diverse sexual and gender identities, including assisting in developing a sensitivity to the continuous, fluid and lifelong development of sexual and gender identity that can be experienced by a person.

\section{Acknowledgements}

This work was primarily supported by the Arcus Foundation, with additional funding support provided by the Multi-Agency Grants Initiative (MAGI) Fund and the University of South Africa. The authors would like to thank the team that assisted in developing the position statement (Ingrid Lynch, Khonzi Mbatha, Carien Lubbe-De Beer, Caretha Laubscher, Diana Breshears, Delene van Dyk, Raymond Nettman, Liesl Theron and Lusajo Kajula), the broader working group (see PsySSA, 2013), the Arcus Foundation, the Humanistisch Instituut voor Ontwikkelingssamenwerking (HIVOS), Clinton Anderson and Ron Schlittler from the APA, Fatima Seedat and the Executive Committee of PsySSA, Saths Cooper and others on the PsySSA Council, as well as all the other individuals and organisations who provided their voice in the creation of the position statement.

\section{References}

Academy of Science of South Africa. (2015). Diversity in human sexuality: Implications for policy in Africa. Pretoria: Author.

American Psychiatric Association. (2013). Highlights of changes from DSM-IV-TR to DSM-5. Washington, DC: American Psychiatric Publishing.

American Psychological Association. (2011). Practice guidelines for LGB clients. Retrieved from http://www.apa.org/pi/lgbt/resources/guidelines.aspx

American Psychological Association. (2015). Guidelines for psychological practice with transgender and gender nonconforming people. Retrieved from http://www.apa.org/practice/guidelines/transgender.pdf doi: 10.1037/a0039906

Anova Health Institute. (2010). From top to bottom: A sex-positive approach for men who have sex with men - a manual for healthcare providers. Retrieved from http://www.glhv.org.au/ files/from_top_to_bottom.pdf

British Psychological Society. (2012). Guidelines and literature review for psychologists working therapeutically with sexual and gender minority clients. Leicester: Author.

Campbell-Hall, V., Peterson, I., Bhana, A., Mjadu, S., Hosegood, V., \& Flisher, A. J. (2010). Collaboration between traditional practitioners and primary health care staff in South Africa: Developing a workable partnership for community mental health services. Transcultural Psychiatry, 47(4), 610-628. doi: 10.1177/1363461510383459

Dartnall, E., \& Jewkes, R. (2013). Sexual violence against women: The scope of the problem. Best Practice \& Research Clinical Obstetrics and Gynaecology, 27, 3-13. doi: 10.1016/j. bpobgyn.2012.08.002

Davies, D. (1996). Towards a model of gay affirmative therapy. In D. Davies \& C. Neal (Eds.), Pink therapy: A guide for counsellors and therapists working with lesbian, gay and bisexual clients (pp. 24-40). Buckingham: Open University Press.

Department of Health. (2006). Ethical rules of conduct for practitioners registered under the Health Professions Act, 1974. Retrieved from http://www.hpcsa.co.za/Conduct/Ethics 
Epprecht, M. (2006). "Bisexuality" and the politics of normal in African ethnography. Canadian Anthropology Society, 48(2), 187-201. doi: 10.2307/25605310

Gender DynamiX. (2011). Indigenous comments on the standards of care for gender identity disorders (6th version). Cape Town: Author.

Hoad, N. (2007). African intimacies: Race, homosexuality, and globalisation. Minneapolis, MN: University of Minnesota Press.

Hong Kong Psychological Society, Division of Clinical Psychology. (2012). Position paper for psychologists working with lesbians, gays, and bisexual individuals. Hong Kong: Author.

Human Rights Watch. (2011). 'We'll show you you're a woman': Violence and discrimination against black lesbians and transgender men in South Africa. New York, NY: Author.

International Psychology Network for Lesbian, Gay, Bisexual, Transgender and Intersex Issues. (2013). Expanded draft version of strategic planning report. Washington, DC: Author.

Jackson, S. (2006). Gender, sexuality and heterosexuality: The complexity (and limits) of heteronormativity. Feminist Theory, 7(1), 105-121. doi:10.1177/1464700106061462

Lynch, I., Brouard, P.W., \& Visser, M.J. (2010). Constructions of masculinity among a group of South African men living with HIV/AIDS: Reflections on resistance and change. Culture, Health \& Sexuality, 12(1), 15-27. doi: 10.1080/13691050903082461

Mertus, J. (2007). The rejection of human rights framings: The case of LGBT advocacy in the US. Human Rights Quarterly, 29(4), 1036-1064. doi: 10.1353/hrq.2007.0045

Milton, M., Coyle, A., \& Legg, C. (2002). Lesbian and gay affirmative psychotherapy: Defining the domain. In A. Coyle \& C. Kitzinger (Eds.), Lesbian and gay psychology (pp. 175-197). Oxford: Blackwell.

Nel, J.A. (2007). Towards the 'good society': Healthcare provision for victims of hate crime from periphery to centre stage (Unpublished doctoral thesis). University of South Africa, Pretoria.

Nel, J.A. (2014). South African psychology can and should provide leadership in advancing understanding of sexual and gender diversity on the African continent. South African Journal of Psychology, 44, 145-148. doi: 10.1177/0081246314530834

Nel, J.A., Rich, E., \& Joubert, K.D. (2007). Lifting the veil: Experiences of gay men in a therapy group. South African Journal of Psychology, 37(2), 284-306. doi: 10.1177/008124630703700205

OUT LGBT Well-being. (2007). Understanding the challenges facing gay and lesbian South Africans: Some guidelines for service providers. Retrieved from http://www.out.org.za/index. $\mathrm{php} / \mathrm{library} / \mathrm{manuals}$

Psychological Association of the Philippines. (2011). Statement of the Psychological Association of the Philippines on non-discrimination based on sexual orientation, gender identity and expression. Philippine Journal of Psychology, 44(2), 229-230.

Psychological Society of South Africa. (2011). Psychological Society of South Africa. Retrieved from http://www.psyssa.com/about-us/what-is-psyssa/

Psychological Society of South Africa. (2013). Sexual and gender diversity position statement. Retrieved from http://www.psyssa.com/wp-content/uploads/2015/12/PsySSA_position_statement_sexual_gender-1.pdf

Republic of South Africa. (1996). Constitution of the Republic of South Africa (Act 108 of 1996). Government Gazette, 38. Pretoria: Government Printers.

Rich, E. (2006). Overall research findings on levels of empowerment among LGBT people in Western Cape, South Africa. Unpublished report, University of South Africa, Pretoria.

Rispel, L.C., \& Metcalf, C.A. (2009). Breaking the silence: South African HIV policies and the needs of men who have sex with men. Reproductive Health Matters, 17(33), 133-142. doi: 10.1016/S0968-8080(09)33442-4

Ritter, K.Y., \& Terndrup, A.I. (2002). Handbook of affirmative psychotherapy with lesbians and gay men. New York, NY: The Guilford Press. 
Smith, T.W. (2011). Cross-national differences in attitudes to homosexuality. GSS Cross-national report no. 31. Retrieved from http://williamsinstitute.law.ucla.edu/wp-content/uploads

Stevens, M. (2012). Transgender access to sexual health services in South Africa: Findings from a key informant survey. Cape Town: Gender DynamiX.

Victor, C.J. (2012, July). African psychological guidelines for LGBTI-affirmative practice: Global and local experience (workshop minutes). Workshop presented at the $30^{\text {th }}$ International Congress of Psychology, Cape Town.

Victor, C.J. (2013). Lesbian, gay and bisexual clients' experience of psychotherapy and counselling: The search for LGBTI-affirmative practice (Unpublished master's dissertation). University of South Africa, Pretoria.

Victor, C.J., \& Nel, J.A. (2016). Lesbian, gay, and bisexual clients' experience with counselling and psychotherapy in South Africa: Implications for affirmative practice. South African Journal of Psychology, 46(3), 351-363. doi:10.1177/0081246315620774

Victor, C.J., Nel, J.A., Lynch, I., \& Mbatha, K. (2014). The Psychological Society of South Africa sexual and gender diversity position statement: Contributing towards a just society. South African Journal of Psychology, 44(3), 292-302. doi:10.1177/0081246314533635

Wells, H. (2005). Overall research findings on levels of empowerment among LGBT people in KwaZulu-Natal. Pretoria: OUT LGBT Well-being.

Wells, H., \& Polders, L. (2003). Gay and lesbian people's experience of the health care sector in Gauteng. Retrieved from http://www.out.org.za/index.php/library/reports

World Professional Association for Transgender Health. (2011). Standards of care for the health of transsexual, transgender, and gender nonconforming people (7th version). Retrieved from http://www.wpath.org/site_page.cfm?pk_association_webpage_menu=1351\&pk_association_webpage $=3926$ 